\title{
Pathogenic Penicillium spp. on Apple and Pear
}

Johannes Petrus Louw and Lise Korsten, University of Pretoria, Department of Microbiology and Plant Pathology, New Agricultural Building, Lunnon Road, Hillcrest, 0083, South Africa

\begin{abstract}
Louw, J. P., and Korsten, L. 2014. Pathogenic Penicillium spp. on apple and pear. Plant Dis. 98:590-598.

Numerous Penicillium spp. have been associated with postharvest fruit spoilage. This study investigates pathogenicity and aggressiveness of selected Penicillium spp. previously isolated from South African and European Union fruit export chains. Penicillium expansum was the most aggressive and $P$. crustosum the second most aggressive on all apple cultivars ('Royal Gala', 'Granny Smith', 'Golden Delicious', 'Topred', and 'Cripps Pink') and two pear cultivars ('Packham's Triumph' and 'Forelle') tested. P. digitatum was the most aggressive on 'Beurre Bosc', 'Beurre Hardy', and 'Sempre' ('Rosemarie') pear cultivars and the third most aggressive on Granny Smith and Cripps Pink

tatum has been described as aggressive on certain pome fruit cultivars. These pear cultivars are also the most commonly associated with decay on the export markets, resulting in considerable end-market losses. $P$ brevicompactum was detected as pathogenic on pear but was not further evaluated in the study. $P$. solitum covered a broader cultivar range, expressed higher disease incidence, and was more aggressive (larger lesions) on pear cultivars than on apple cultivars. This study provides new information on host specificity and the importance of pathogenic Penicillium spp. isolated from various environments in the shipping and marketing channels.
\end{abstract} apple cultivars. To our knowledge, this is the first report where $P$. digi-
The South African pome fruit industry is economically important in terms of global trade. The industry produces over 1.1 million tons of fruit, of which $46.6 \%$ are exported as fresh produce, earning close to $\$ 431.6$ million in net export realization in 2012 (9). Postharvest losses have been reported as high as 50\% in developing countries $(5,21,29)$. Significant losses have been attributed to decay caused by Penicillium spp. (12,14,16,19,22,32).

A report by Sanderson and Spotts (22) indicates that numerous Penicillium spp. naturally inhabit pome fruit environments (packinghouses and storage facilities) and are prominent on fruit bins. Of these species, Penicillium expansum Link, P. crustosum Thom, and $P$. solitum Westling have been described as the most important on apple (Malus domestica L. Borkh.) and pear (Pyrus communis L.) in causing decay $(14,22,32)$. Other pathogenic species reported include Penicillium aurantiogriseum Dierckx, P. brevicompactum Dierckx, $P$. commune Thom, $P$. griseofulvum Dierckx, $P$. verrucosum, Dierckx, and P. carneum (Frisvad) Frisvad (2,12,16,18,23). However, these species have less often been associated with decay of pome fruit.

Several other Penicillium spp. isolated from pome fruit environments $(2,22)$ are best known as pathogens on other fruit crops. These include $P$. digitatum (Pers.) Sacc. on citrus (8) and $P$. glabrum (Wehmer) Westling on pomegranate (3). Complex fruit trade networks result in a large variety of fruit from different countries

Corresponding author: J. P. Louw, E-mail: pieterjplouw @gmail.com

* The $\boldsymbol{e}$-Xtra logo stands for "electronic extra" and indicates that a supplementary figure is available in the online edition.

Opinions, findings, and conclusions or recommendations expressed in any publication generated by the National Research Foundation of South Africa (NRF)-supported research are those of the authors and that the NRF accepts no liability whatsoever in this regard.

Accepted for publication 8 November 2013.

http://dx.doi.org/10.1094/PDIS-07-13-0710-RE

(C) 2014 The American Phytopathological Society being retained together in storage or holding facilities (34). In addition, citrus and pome fruit are sometimes repacked in the same facility to remove decaying fruit. This practice can potentially introduce a wider range of pathogens to the hosts that would not otherwise encounter these pathogens. Recently, Vilanova et al. (35) reported $P$. digitatum as able to infect 'Golden Smoothee' apple but with lesions not developing beyond the initial infection site. Infectivity was described as limited to specific fruit maturity conditions (commercial and over-mature) and inoculum load, resulting in peel infection reactions of up to $6 \mathrm{~mm}$ in diameter (including the wound site).

The lack of transparency, more specifically toward the end of the supply chain, makes it difficult to assess the impact of pathogen presence and the inoculum load. Costs associated with market-end losses are often passed back to the farmer without verification of the causal agent or possible point of contamination. End-of-theseason fruit, long-term storage, and extended transit periods can result in physiologically older end-market produce that may be more susceptible toward decay $(4,10,15,36)$. In this context, opportunistic pathogens encountered further down the supply chain may infect fruit previously considered nonhosts for those pathogens.

The aim of this research project was to evaluate representative dominant Penicillium spp. isolated from various environments in the citrus and pome fruit supply chains and to determine pathogenicity, aggressiveness, and host specificity of these isolates. This knowledge will provide a better understanding of the causal agents, inoculum buildup, and fruit decay at the market end of the supply chain.

\section{Materials and Methods}

Fungal cultures. The Penicillium spp. isolates were obtained from the fungal culture collection at the University of Pretoria. Isolates came from pear (2010-11) and citrus (2009-10) export chain studies (unpublished data) (Table 1). The criterion for initial selection of species from the culture collection for the present study was based on the identified species being well-known pathogens or the species representing dominance in the supply chain environment. Cultures of the isolates for experimental trials were prepared by single-spore isolation. Cultures were grown for up to 3 
weeks on malt extract agar (MEA) (Merck, Biolab Diagnostics [Pty.] Ltd.) plates in darkness at $25^{\circ} \mathrm{C}$. Original isolates were previously purified, morphologically grouped, molecularly identified, and preserved in water as working cultures and in $10 \%$ glycerol for long-term storage. Water preservations were made by placing five to six pieces of the fungal mycelial growth culture on MEA into double-sterilized distilled water in McCartney bottles, which were parafilmed and stored at room temperature. Cryo-preservation was made by placing five to six pieces of MEA-grown cultures into $10 \%$ glycerol (autoclaved five times) in cryotubes, which were stored at $-72^{\circ} \mathrm{C}$ in a freezer.

The isolates were identified by a polymerase chain reaction restriction fragment length polymorphism (PCR-RFLP) method and identity was confirmed by sequencing. DNA was extracted using Neuclospin Plant II kit (Macherey-Nagel GmbH and Co. KG), PCR amplified, restriction digested $(11,17,19)$, and submitted for sequencing to conduct final identification. The PCR reactions were performed in a 2700 Perkin-Elmer PCR thermocycler using $\beta$ tubulin primers (Bt2a and $\mathrm{Bt} 2 \mathrm{~b}$ ) (7). The cycle conditions included a preliminary $3 \mathrm{~min}$ denaturation step at $95^{\circ} \mathrm{C}$; 35 cycles of denaturation $\left(94^{\circ} \mathrm{C}\right.$ for $\left.30 \mathrm{~s}\right)$, annealing $\left(57^{\circ} \mathrm{C}\right.$ for $\left.45 \mathrm{~s}\right)$, and elongation $\left(72^{\circ} \mathrm{C}\right.$ for $\left.2 \mathrm{~min}\right)$; followed by a final elongation step $\left(72^{\circ} \mathrm{C}\right.$ for 7 min); and samples were held at $4^{\circ} \mathrm{C}$ upon completion. The yield, purity, and quality of PCR amplicons were verified on an agarose gel with a 1-kb ladder/marker.

Restriction enzyme BfaI (isochitzomer, FspBI; Inqaba) was used to restriction digest the PCR amplicons. The fragments were separated by electrophoresis on $3 \%$ agarose gel run at $75 \mathrm{~V}$ for 3 to $5 \mathrm{~h}$ (minimum and maximum run time) with a 100-bp ladder/marker to separate the fragment and determine polymorphisms. For sequencing, the PCR amplicons were purified according to MSB Varo CleanUp (Invitek GmbH). The sequencing of PCR samples was conducted with the BigDye Terminator V3.1 Cycle Sequencing Kit (Applied Biosystems) including the forward primer (Bt2a). Sequence cycle profiles followed in a 2700 Perkin-Elmer PCR thermocycler. The cycle conditions were $96^{\circ} \mathrm{C}$ for 1 min followed by 25 cycles $\left(96^{\circ} \mathrm{C}\right.$ for $10 \mathrm{~s}, 50^{\circ} \mathrm{C}$ for $5 \mathrm{~s}$, and $60^{\circ} \mathrm{C}$ for $\left.4 \mathrm{~min}\right)$, and samples were held at $4^{\circ} \mathrm{C}$. The sequenced PCR products were analyzed with an ABI3500 Genetic Analyzer (Applied Biosystems).

Confirming pathogenicity and comparing citrus isolates to pear isolates. The Penicillium spp. selected for pathogenicity trials included isolates from the citrus environment ( $P$. expansum, $P$. crustosum, $P$. solitum, $P$. digitatum, and $P$. brevicompactum). Spore suspensions were prepared in sterilized Ringers (Merck) solution containing 0.05\% Tween 80 (Associated Chemical Enterprises). Concentration of the spore suspensions were determined with a hemocytometer and the suspensions were diluted to the final concentrations of $6.3 \times 10^{4}$ conidia/ml. Freshly harvested, untreated, commercial-grade mature apple ('Golden Delicious') and pear ('Beurre Hardy') from a packinghouse in the Western Cape Province with different postharvest practices were used in the pathogenicity trials (Table 2). Fruit were surface sterilized by dipping them into $0.002 \%$ sodium hypochlorite solution for approximately $10 \mathrm{~min}$ and allowed to air dry. In all, 10 apple fruit and 10 pear fruit were inoculated with each isolate of Penicillium. Each fruit was wounded on opposite sides ( 1.5 by 1.5 by $3 \mathrm{~mm}$ ) by gently piercing the fruit surface with a sterile yellow micropipette tip. Inoculation was conducted by depositing $20 \mu \mathrm{l}$ of spore suspension into each wound using a pipette. Controls consisted of uninoculated wounded fruit. All wounds (inoculated and uninoculated) were taped with Parafilm to prevent cross-contamination during the experiment. Fruit were randomized on a disinfected table and incubated under ambient conditions $\left(24.1 \pm 0.9^{\circ} \mathrm{C}\right.$ and $48.8 \pm 5.8 \%$ relative humidity $[\mathrm{RH}]$ ) for 7 days. The decay was assessed 3, 5, and 7 days post inoculation by measuring the horizontal and vertical (stem-calyx axis vertical) diameters of lesions. Control wound sizes were also measured and mean diameters of control wounds were subtracted from the measured lesion diameters. The experiment was repeated and arranged according to the complete randomized design.

The citrus isolates that were confirmed pathogenic to apple and pear were further evaluated to observe whether they can be considered pathogenic representatives of their species by comparing them with environmental isolates from a pear chain study. The isolates included $P$. expansum, $P$. crustosum, $P$. solitum, and $P$. digitatum. This comparative trial was conducted by inoculating five surfacesterilized pear fruit (Beurre Hardy) per isolate using the spore suspension method. Inoculation and incubation of the fruit and the

Table 2. Pome fruit origin and handling practices

\begin{tabular}{|c|c|c|c|}
\hline Trial, cultivar & Season $^{x}$ & Practices $^{\mathrm{y}}$ & $\begin{array}{c}\text { Storage } \\
\text { (days) }^{\mathrm{z}}\end{array}$ \\
\hline \multicolumn{4}{|l|}{ Pathogenicity and cold storage } \\
\hline Golden Delicious & Mid & A & $18 / 20$ \\
\hline Beurre Hardy & Late & $\mathrm{A}$ & $12 / 13$ \\
\hline \multicolumn{4}{|l|}{ Isolate comparison } \\
\hline Beurre Hardy & Late & A & 32 \\
\hline \multicolumn{4}{|l|}{ Aggressiveness } \\
\hline Golden Delicious & Mid & A & $12 / 13$ \\
\hline Granny Smith (2012) & Late & A & 31 \\
\hline Granny Smith (2011) & Previous & $\mathrm{B}$ & $12 / 13$ \\
\hline Cripps Pink & Late & $\mathrm{B}$ & 31 \\
\hline Topred & Late & $\mathrm{C}$ & $1 / 2$ \\
\hline Royal Gala & Mid/Late & $\mathrm{D}$ & $8 / 12$ \\
\hline Packham's Triumph (region 1) & Early & $\mathrm{D}$ & $8 / 12$ \\
\hline Packham's Triumph (region 2) & Mid & $\mathrm{E}$ & $1 / 2$ \\
\hline Forelle & Early/Mid & $\mathrm{E}$ & $1 / 2$ \\
\hline Beurre Hardy & Late & $\mathrm{A}$ & $12 / 13$ \\
\hline Beurre Bosc & Mid & $\mathrm{D}$ & $8 / 12$ \\
\hline Sempre (Rosemarie) & Mid & $\mathrm{D}$ & $8 / 12$ \\
\hline
\end{tabular}

$\mathrm{x}$ Time of harvest $=$ period when the fruit was harvested within the season. Previous $=$ previous year (long term storage)

y Postharvest practices. $\mathrm{A}=$ Standard packaging (eight $1.5-\mathrm{kg}$ bags per box) and conventional transport (commercial transport via truck) to Tshwane Fresh Produce Market; B = standard packaging (layering in box) and commercial transport to Tshwane Fresh Produce Market; $\mathrm{C}=$ sent directly from the farm (loose packed in box) and commercial transport to Tshwane Fresh Produce Market; D = standard packaging (layering in box), flown (cargo) to O.R. Tambo International Airport; and E = standard packaging (layering in box) and commercial transport to Tshwane Fresh Produce Market.

${ }^{\mathrm{z}}$ Cold storage before inoculation.

Table 1. Penicillium isolates used in the pome fruit studies

\begin{tabular}{llllll}
\hline Isolate code & \multicolumn{1}{c}{ Penicillium spp. } & Fruit chain & Year & Country of origin & Source (location of isolation) \\
\hline P.eC & Penicillium expansum & Citrus & $2009-10$ & Germany & $\begin{array}{l}\text { Distributer/repack facility-wall; } \\
\text { Koch postulates confirmed on apple (2011) } \\
\text { Cold storage facility, air }\end{array}$ \\
P.eP & P. expansum & Pear & 2011 & United Kingdom & Packinghouse air, wall or floor \\
P.cC & P. crustosum & Citrus & $2009-10$ & Germany & Packinghouse holding area, wall \\
P.cP & P. crustosum & Pear & 2011 & South Africa & Distributer/repack facility, wall \\
P.sC & P. solitum & Citrus & $2009-10$ & Germany & Retail storage facility, wall \\
P.sP & P. solitum & Pear & 2011 & United Kingdom & Distributer/repack facility, floor; \\
P.dC & P. digitatum & Citrus & $2009-10$ & Netherlands & Koch postulates confirmed on plum (2011) \\
& & & & & Repack facility area small waste bins \\
P.dP & P. digitatum & Pear & 2011 & United Kingdom & Distribution center, air \\
P.bP & P. brevicompactum & Pear & 2010 & United Kingdom & \\
\hline
\end{tabular}


measuring of lesion diameters were as previously described. The isolate comparison trial was repeated and using a complete randomized design.

Decay caused by Penicillium spp. under cold-storage conditions. The cold-storage trial was performed to determine effect of temperature on disease expression on Golden Delicious apple (Table 2) inoculated with $P$. expansum, $P$. crustosum, $P$. digitatum, and $P$. solitum isolated from a citrus environment. Each pathogen was inoculated to 10 surface-sterilized apple fruit using the spore suspension method. One set of inoculated apple fruit was incubated under ambient conditions whereas the second group was incubated under refrigerated conditions $\left(6.2 \pm 1.7^{\circ} \mathrm{C}\right.$ and $\left.63.3 \pm 3.0 \% \mathrm{RH}\right)$. During the 43-day incubation period, the lesion diameters were recorded (as previously described) every second day starting from the third day after inoculation. Mean wound sizes for controls were also subtracted from the measured lesion diameter means to present decay lesion diameter alone. The trial included a repeat with factorial arrangements on a complete randomized block design.

Aggressiveness of Penicillium spp. on apple and pear cultivars. Five different apple (Golden Delicious, 'Granny Smith', 'Royal Gala', 'Topred' and 'Cripps Pink') and five different pear (Beurre Hardy, 'Beurre Bosc', 'Forelle', 'Packham's Triumph' and 'Sempre' ('Rosemarie']) cultivars were inoculated with citrus environment isolates of $P$. expansum, $P$. crustosum, $P$. digitatum, and $P$. solitum using the spore suspension inoculation method. Fruit for the test originated from two packinghouses in the Western Cape Province but were collected from various sectors in the supply chain ranging from freshly harvested (fully mature) to packed or commercially stored (Table 2). Ten surface-sterilized fruit per Penicillium sp. per cultivar were inoculated with the pathogens and incubated under ambient conditions, and the lesion diameters were measured as previously described. Mean wound sizes for the controls were subtracted from the measured lesion diameter means in the results. Symptom expression (necrotic pattern, visual fungal growth, and sporulation) and disease progression were recorded. The experiment was repeated and organized according to a factorial arrangement on a complete randomized design.

Isolations from lesions, culture preservation, and Penicillium spp. identification. Two to three fruit from all experiments were selected for each cultivar or combination tested for reisolation of the pathogen. Isolations were made onto MEA medium and incubated as previously described. Once sufficient growth occurred, the cultures were observed for morphological similarity and purity and one culture for each Penicillium sp. from each cultivar or combination was preserved and identified using the genetic approach, as previously described.

Statistical analysis. Statistical analysis was performed with SAS (version 9.2; SAS Institute Inc.). Each fruit in every trial was treated as a replicate, with its mean derived from four measurements (two wounds with horizontal and vertical diameter measurements), with means \pm standard deviation. The least-square mean $t$ test was used to analyze similarity between repeated tests. The independent experiments for all the trials proved not significantly different and, thus, were pooled. Fisher's least significant difference was used to separate means.

Lesion diameter (in millimeters) and disease incidence (percentage) of the inoculated wounds from the pathogenicity trials were recorded and used to calculate disease intensity, a measure that represents the combined effect of disease severity and disease incidence. Lesions significantly different from the control were regarded as significant infection reactions and used in calculating disease incidence. Disease intensity can be used to compare the potential importance of each Penicillium sp. on the respective crop, indicating possible disease-associated concerns within the fresh produce chain. The disease intensity relation is as follow: disease intensity $=\left[(d \times F) /\left(T_{\mathrm{n}} \times D\right)\right] \times 100$, where $d=$ degree of disease severity assessed or specific lesion size classified on the empirical scale, $F=$ frequency, $T_{\mathrm{n}}=$ total number of fruit examined, and $D=$ highest numerical number value of the empirical scale used (33). The relation was applied with mean lesion diameter $(d)$, number of pathogenic reactions observed $(F)$, total number of inoculated wounds examined $\left(T_{\mathrm{n}}\right)$, and maximum lesion diameter measurable $(D)$.

\section{Results}

Confirming pathogenicity and comparing citrus isolates to pear isolates. The independent pathogenicity experiments (trial and repeat) for both apple and pear did not differ significantly $(P=$ 0.57 and $P=0.89$ ). However, different host-pathogen interactions did differ significantly (Table 3 ). All of the Penicillium spp. originating from a citrus environment were pathogenic on pear. Fewer Penicillium spp. were pathogenic on apple compared to pear. $P$. brevicompactum was not pathogenic, whereas $P$. solitum and $P$. digitatum expressed low incidence and small lesions on apple fruit within the 7-day period assessed. Mean lesion diameters caused by $P$. solitum and $P$. digitatum on apple did not differ significantly when compared with the control but some significantly different lesions were noted to calculate disease intensity (Table 3 ).

Lesion sizes were not significantly different in two independent experiments for isolate comparison on pear $(P=0.85)$. The pear and citrus isolates also did not differ significantly in terms of lesion sizes (Fig. 1).

Decay caused by Penicillium spp. under cold-storage conditions. The temperature had a significant impact on rate of lesion development $(P<0.0001)$. The cold-storage trial and repeat did not differ significantly $(P=0.80)$. $P$. expansum was the only

Table 3. Apple and pear pathogenicity and disease intensity results ${ }^{\mathrm{w}}$

\begin{tabular}{|c|c|c|c|c|}
\hline Cultivar, Penicillium spp. & $\begin{array}{l}\text { Mean of all inoculated } \\
\text { wounds }(\mathbf{m m})^{\mathrm{x}}\end{array}$ & $\begin{array}{c}\text { Mean of significant } \\
\text { lesions }(\mathbf{m m})^{x, y}\end{array}$ & $\begin{array}{c}\text { Incidence } \\
\text { (significant lesions) }(\%) \\
\end{array}$ & $\begin{array}{c}\text { Disease intensity } \\
(\%)^{\mathrm{z}} \\
\end{array}$ \\
\hline \multicolumn{5}{|l|}{ Beurre Hardy } \\
\hline Penicillium expansum & $34.1 \pm 3.2 \mathrm{~b}$ & $34.1 \pm 3.2$ & 100 & 36.3 \\
\hline P. crustosum & $29.5 \pm 4.5 \mathrm{~b}$ & $29.5 \pm 4.5$ & 100 & 31.1 \\
\hline P. solitum & $8.1 \pm 3.3 \mathrm{dc}$ & $9.8 \pm 2.2$ & 70 & 7.3 \\
\hline P. digitatum & $81.7 \pm 11.1 \mathrm{a}$ & $81.7 \pm 11.1$ & 100 & 87.0 \\
\hline P. brevicompactum & $3.7 \pm 2.7 \mathrm{de}$ & $8.4 \pm 0.9$ & 20 & 1.8 \\
\hline Control & $0.1 \pm 0.2 \mathrm{e}$ & 0 & 0 & 0 \\
\hline \multicolumn{5}{|l|}{ Golden Delicious } \\
\hline P. expansum & $27.3 \pm 3.9 \mathrm{a}$ & $27.3 \pm 3.9$ & 100 & 27.1 \\
\hline P. crustosum & $12.5 \pm 3.5 \mathrm{~b}$ & $12.5 \pm 3.5$ & 100 & 12.4 \\
\hline P. solitum & $1.5 \pm 1.1 \mathrm{c}$ & $2.6 \pm 0.5$ & 40 & 1.1 \\
\hline P. digitatum & $1.5 \pm 1.4 \mathrm{c}$ & $4.0 \pm 0.6$ & 20 & 0.8 \\
\hline P. brevicompactum & $0.2 \pm 0.1 \mathrm{c}$ & 0 & 0 & 0 \\
\hline Control & $0.0 \pm 0.1 \mathrm{c}$ & 0 & 0 & 0 \\
\hline
\end{tabular}

\footnotetext{
${ }^{\mathrm{w}}$ Means followed by \pm standard deviation.

${ }^{\mathrm{x}}$ Mean wound diameter for controls were already subtracted from measured lesion diameters. Letters that are dissimilar are significantly different.

${ }^{y}$ Only lesions significantly different from the control was used to calculate these means (nonsignificant lesions were excluded).

${ }^{\mathrm{z}}$ Disease intensity $=\left[(d \times F) / T_{\mathrm{n}} \times D\right] \times 100$, where $D$ pear fruit $=93.95 \mathrm{~mm}$ and apple fruit $=100.48 \mathrm{~mm}$.
} 


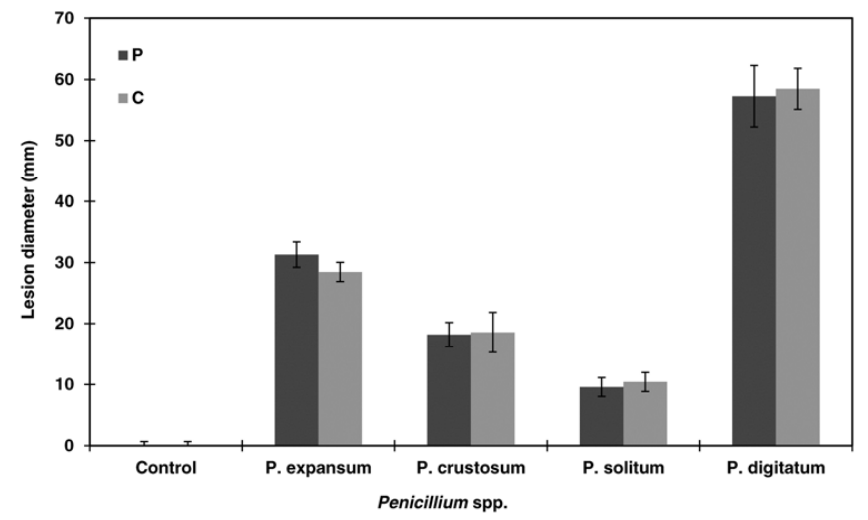

Fig. 1. Lesion diameters (7 days of incubation at ambient conditions) caused by different Penicillium spp. isolates infecting 'Beurre Hardy' pear; $\mathrm{P}=$ pear and $\mathrm{C}=$ citrus supply-chain isolates.

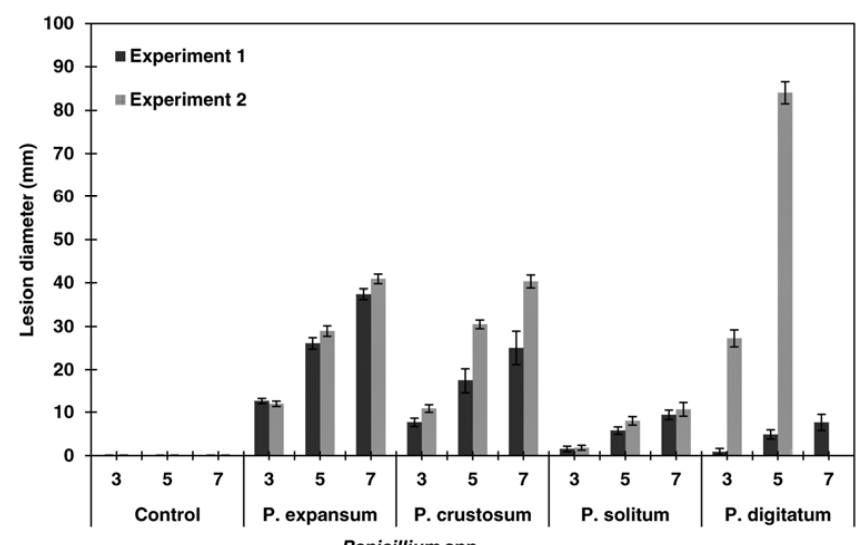

Penicillium spp.

Fig. 2. Penicillium spp. lesion diameter growth on 'Beurre Bosc' pear over 7 days of incubation at ambient conditions in two individual experiments. species able to cause symptoms on Golden Delicious under coldstorage conditions over the 43 day storage period (lesion diameter $[l d]=49.5 \pm 17.3 \mathrm{~mm}$ ). However, $P$. crustosum did produce small lesions of $4.0 \pm 0.5 \mathrm{~mm}$ (mean wound diameter of the control was already subtracted) at low incidence (10\%) under the cold-storage conditions. Under ambient conditions (17 days), large lesions were caused by $P$. expansum $(73.9 \pm 9.2 \mathrm{~mm})$ and $P$. crustosum $(42.2 \pm$ $12.4 \mathrm{~mm})$. $P$. digitatum and $P$. solitum again caused small lesions at low incidence on Golden Delicious apple. The experiment was terminated on the 17th day due to total decay of fruit by $P$. expansum at ambient conditions. Under cold-storage conditions, lesions began to develop 7 days post inoculation while fruit kept under ambient conditions developed decay 2 days post inoculation. No surface mycelium or sporulation was observed on inoculated fruit kept in cold storage. Fruit inoculated with $P$. expansum and stored under ambient conditions displayed mycelial growth on the fruit surface after 6 days (no sporulation noted).

Aggressiveness of Penicillium spp. on apple and pear cultivars. The Penicillium-cultivar interactions were significantly different $(P<0.0001)$. The repeated experiments were not significantly different, except for $P$. digitatum on Beurre Bosc pear where, in the initial experiment, small lesions (7-day $l d=7.6 \pm 3.7$ $\mathrm{mm}$ ) were observed compared with large lesions (5-day $l d=84.0 \pm$ $5.2 \mathrm{~mm}$ ) in the second experiment. A similar shift in aggressiveness occurred on Beurre Bosc inoculated with P. crustosum between the two experiments but differences were not as large (25.0 $\pm 7.7 \mathrm{~mm}$ versus $40.3 \pm 3.0 \mathrm{~mm}$ ) (Fig. 2). The same cultures were used for inoculation but, in the second experiment, the fruit were presumed to be riper because they were kept in cold storage 4 days longer (Table 2). Due to differences in production practices, cultivar availability, or seasonality, the trial experiments could not be completed simultaneously $(15,36)$.

Decay development by $P$. expansum and $P$. crustosum over the cultivar ranges were more consistent compared with $P$. digitatum and $P$. solitum. $P$. digitatum and $P$. solitum did not cause decay on Royal Gala apple (Fig. 3). The mean of lesions caused by $P$. digitatum on Packham's Triumph (region 1) were not significantly different from the control but few independent lesions were noted as

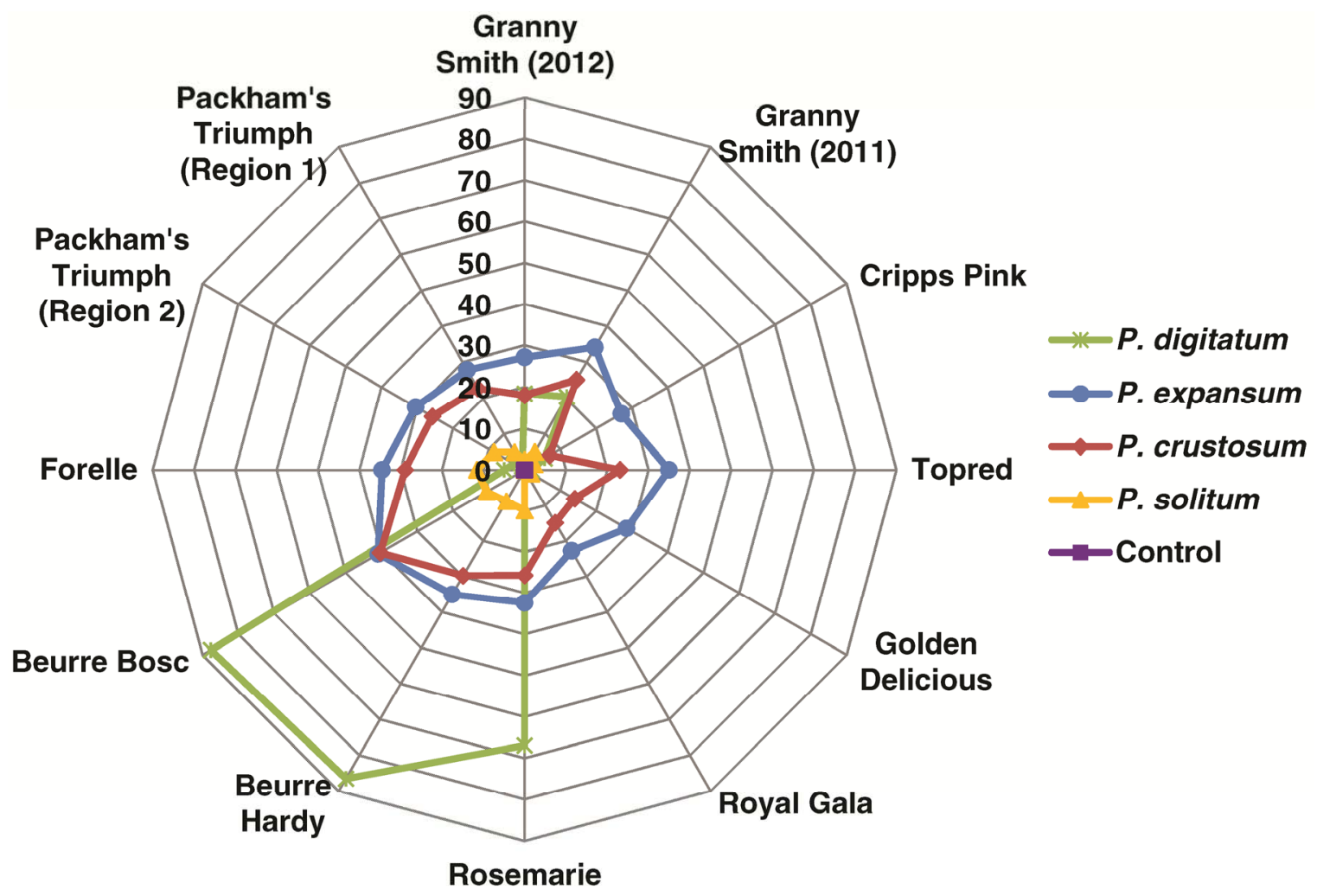

Fig. 3. Lesion diameter (in millimeters) of Penicillium spp.-inoculated apple and pear cultivars after 7 days of incubation at room conditions. 
significantly different; $10.5 \%$ of the inoculated wounds had lesions $4.7 \pm 1.3 \mathrm{~mm}$ in diameter. $P$. digitatum lesion decay on the remaining cultivars were significantly different from the control; however, incidences (only lesions significantly different from the control were regarded as significant infection reactions) varied with some (Table 4). P. digitatum was the most aggressive species on Beurre Bosc (100.0\% fifth-day incidence with $l d=83.9 \pm 5.2 \mathrm{~mm}$ for the second experiment), Beurre Hardy (100.0\% seventh-day lesion incidence with $l d=84.7 \pm 8.4 \mathrm{~mm}$ ), and Rosemarie (100.0\% seventhday incidence with $l d=73.6 \pm 11.5 \mathrm{~mm}$ ). $P$. solitum lesions on all the cultivars, except Royal Gala, were significantly different compared with the control but incidence also varied (Table 4). In general, greater incidence and larger lesions were observed from the Penicillium spp. on pear than on apple fruit (Fig. 3).

Symptom expression on apple and pear cultivars. Expressions of decay symptoms on various cultivars were compared with previously described symptoms caused by $P$. expansum, $P$. crustosum, $P$. solitum, and $P$. digitatum. This study noted additional symptoms not previously described from various Penicillium pathogens screened on different cultivars. Symptom expression was not uniform on different cultivars. The lesions produced on all apple and pear cultivars tested were brown, circular, and slightly sunken. The shade of the brown lesions differed depending on the Penicillium spp. and the cultivar host they infect. Thus, lesion coloration cannot be associated with either a specific species or cultivar but, rather, with an interaction between Penicillium sp. and fruit cultivar (Figs. 4 and 5). P. digitatum also produced not distinctly defined lesions with brown blotching and softening and swollenness of the tissue, later resulting in a bulged appearance of browned skin on sensitive hosts (Fig. 6). These lesions can be seen during development from a central infection point or, as in the case of Granny Smith appearing 5 to 6 days after inoculation, from below the skin surface. In the latter case, the skin of the apple will appear healthy during the first few days but the application of pressure reveals a hollowing or softening underneath the skin surface. $P$. expansum and $P$. crustosum frequently produced bull's-eye rot-type symptoms as the growth progressed on all cultivars (Figs. 4 and 5). $P$. solitum produced very small lesions on apple fruit when inoculated into susceptible hosts. Some apple cultivars displayed typical resistant response reactions (avirulence, as described by Agrios [1]) as skin or tissue darkening that were restricted to the inoculated wound areas (Fig. 4, P. solitum reactions on Granny Smith, Golden Delicious, and Topred; $P$. digitatum reactions on Golden Delicious and Topred). Avirulent reactions were also observed on a

Table 4. Penicillium digitatum and $P$. solitum disease and infection reactions with incomplete incidence (>100\%) after 7 days of incubation on tested apple and pear cultivars

\begin{tabular}{lcc}
\hline Penicillium spp., cultivar & $\begin{array}{c}\text { Mean of significant } \\
\text { lesions }^{\mathbf{z}}\end{array}$ & $\begin{array}{c}\text { Incidence } \\
(\mathbf{\%})\end{array}$ \\
\hline P. digitatum & & \\
Topred & $4.0 \pm 2.3$ & 27.8 \\
Golden Delicious & $3.1 \pm 1.1$ & 27.5 \\
Cripps Pink & $6.6 \pm 3.9$ & 81.8 \\
Granny Smith 2011 & $20.3 \pm 12.7$ & 97.3 \\
Granny Smith 2012 & $19.1 \pm 8.8$ & 96.8 \\
Packham's Triumph (region 2) & $7.0 \pm 2.7$ & 51.3 \\
Forelle & $7.1 \pm 3.1$ & 64.5 \\
P. solitum & $3.4 \pm 0.8$ & \\
Topred & $3.0 \pm 1.1$ & 30.0 \\
Golden Delicious & $4.5 \pm 1.8$ & 35.0 \\
Cripps Pink & $5.0 \pm 2.4$ & 40.0 \\
Granny Smith 2011 & $4.3 \pm 1.9$ & 89.5 \\
Granny Smith 2012 & $5.8 \pm 2.6$ & 70.0 \\
Packham's Triumph (region 1) & $6.9 \pm 3.4$ & 85.0 \\
Packham's Triumph (region 2) & $8.4 \pm 3.4$ & 90.0 \\
Beurre Hardy & $8.4 \pm 3.2$ & 88.2 \\
Rosemarie & \\
\hline
\end{tabular}

${ }^{\mathrm{z}}$ Only lesions significantly different from the control were used to calculate these means (nonsignificant lesions were excluded). Means \pm standard deviation. few independent Packham's Triumph pear fruit inoculated with $P$. digitatum.

$P$. expansum and $P$. crustosum produced white mycelia on all apple cultivars, although the amount produced by $P$. expansum made it more apparent. $P$. solitum and $P$. digitatum produced only small amounts of mycelia when infecting Granny Smith and Cripps Pink. No Penicillium spores were observed on any apple cultivars for the duration of the experiment. Mycelial growth with limited sporulation was observed on all pear cultivars inoculated with $P$. expansum and $P$. crustosum. $P$. solitum never sporulated but mycelial growth was observed on all pear cultivars. $P$. digitatum produced very limited mycelia and spores on the large lesions produced on Beurre Bosc. More sporulation was noted on Beurre Hardy, with Rosemarie supporting profuse sporulation after 7 days of incubation. No mycelial growth or spores were on the remaining pear cultivars inoculated with $P$. digitatum. $P$. expansum and $P$. crustosum typically produced blue spores (blue mold) whereas $P$. digitatum produced lime-green spores (green mold) (Fig. 6).

Confirmation of identity. Koch's postulates were confirmed on all species tested in the trails. The identity of the Penicillium spp. reisolated from infected fruit were confirmed using PCR-RFLP and sequencing from the same species that were used for the inoculation of the fruit (Table 5).

\section{Discussion}

The most important pathogenic Penicillium spp. in terms of decay on pome fruit identified in this study were $P$. expansum, $P$. crustosum, $P$. digitatum, and $P$. solitum. These species have formerly been described in pome fruit environments $(2,22)$ and as pathogenic (excluding $P$. digitatum) on pome fruit $(14,22,32)$. Sanderson and Spotts (22) previously reported isolating $P$. digitatum with low incidence (1.8\% of 57 pear fruit) from decay lesions on winter pear ('d'Anjou', 'Bosc', 'Comice', and 'Red Anjou'). In their study, decaying apple and pear fruit were sampled from both packinghouses and local markets. The sampling from the packinghouses was regarded as biased because samples were selected based on a specific type of decay. Nonetheless, $P$. digitatum was only isolated from the market winter pear and were not pathogenic when inoculated into fresh d'Anjou pear. The authors never demonstrated or explicitly stated that $P$. digitatum pathogenic on pear but theorized that the species may be able to colonize "over-mature" fruit (market fruit).The authors did not screen a spectrum of different cultivars or test physiologically older fruit obtained from the market (22). P. brevicompactum was found to be nonpathogenic on apple and was not tested further in this study.

$P$. digitatum produced the largest lesions on three cultivars (Rosemarie, Beurre Bosc, and Beurre Hardy), indicating its importance as a postharvest pathogen on pear. These cultivars were also identified by the industry as the cultivars experiencing concerning losses in the export markets. To our knowledge, this is the first report where $P$. digitatum was described as a highly aggressive pathogen on selected pear cultivars. $P$. digitatum infections are more prominently associated with over-mature fruit $(22,35)$, possibly causing problems much later in the market chain, similar to our results in the second experiment on Beurre Bosc. Although fruit for both trials were selected at commercial harvest maturity stage, fruit for the second experiment was refrigerated $\left(6.2 \pm 1.7^{\circ} \mathrm{C}\right) 4$ days longer (total of 12 days) before inoculation trials. Storage at 5 to $10^{\circ} \mathrm{C}$ for 3,5 or 7 days enhances pear ripening (36), thus influencing susceptibility toward decay $(10,35)$. The prolonged storage at the specified temperature is a potential explanation for the fruit being more mature and, thus, more susceptible toward decay. $P$. expansum lesion development was less affected by the prolonged stored fruit, although $P$. crustosum was influenced. This raises the question of whether $P$. crustosum should be regarded more problematic on pear after suboptimum storage or transport of the fruit. It also illustrates that stored or transported fruit may become more susceptible toward certain pathogenic Penicillium spp. Effective cold-chain management and reduction of inoculum loads still remain important for disease control. 
Although fruit maturity indexes for each cultivar were not tested in the lab prior to inoculation in this study, the fruit were all commercially handled and, as a batch, officially inspected for compliance with national quality standards and maturity according to the Agricultural Products Standards Act Number 119 of 1990 (27,28). Through this study, we have come to understand the importance of taking fruit seasonality and postharvest changes into account in pathogenicity or aggressiveness studies. Some reports dealing with pathogenicity or aggressiveness do not test or report on the physiological status of the host $(2,16,31)$. However, this aspect should be included to more effectively assess host-pathogen interactions in the future.
It is important to consider further steps in the supply chain when fruit is stored for months prior to packaging and marketing. Fruit designated for export markets with long distribution systems will be more prone to decay, because fruit will be more mature after a long sea shipment (16 days or longer) and may be exposed to pathogens from other fruit species (e.g., citrus and apple when seasons overlap) that may be handled in the same central facility. In addition, during repacking, the cold chain is broken and the fruit can be wounded and exposed to Penicillium inoculum that can cause decay (34) at the consumer end of the chain. P. digitatum in this study has been identified as a pathogen that has the potential to cause rapid decay at the market end (total fruit decay within 5

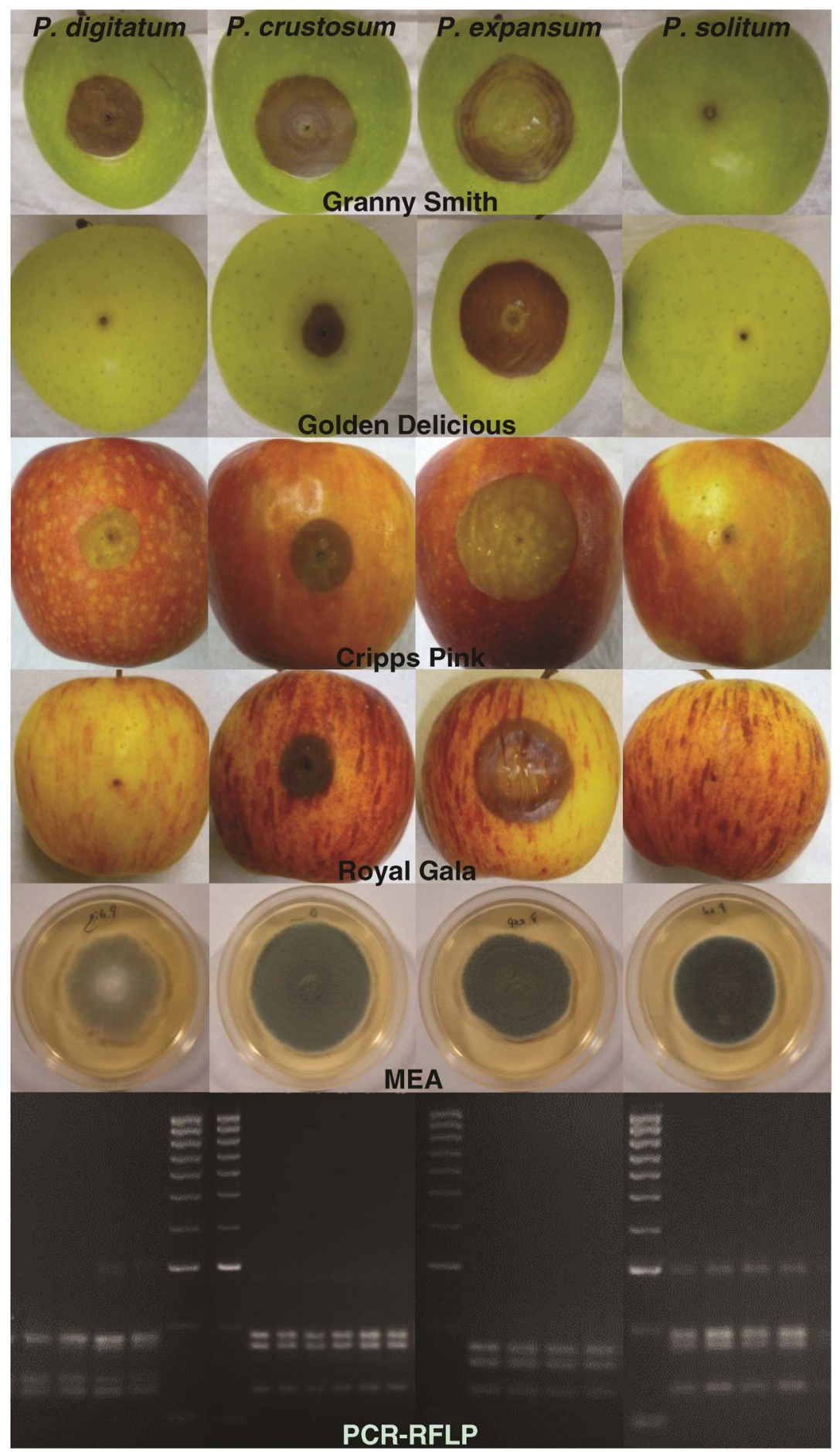

Fig. 4. Penicillium sp. (columns, left to right: Penicillium digitatum, $P$. crustosum, $P$. expansum, and $P$. solitum) symptom expression on apple cultivars (rows, top to bottom: 'Granny Smith', 'Golden Delicious', 'Cripps Pink', and 'Royal Gala'), cultures (malt extract agar [MEA]), and polymerase chain reaction restriction fragment length polymorphism (PCR-RFLP) of restriction-digested DNA (Bfal restriction enzyme) separated on $3 \%$ agarose gel. 
days), especially when fruit are riper. Therefore, pathogenicity trials on market-aged fruit are required to identify the pathogens that can cause rapid decay and extensive losses at the end of market chain.
Sanderson and Spotts (22) noted that $P$. digitatum probably colonizes over-mature fruit because they isolated the species from market pear but could not reproduce infections on newly harvested pear fruit. Unfortunately, no symptom descriptions were given of

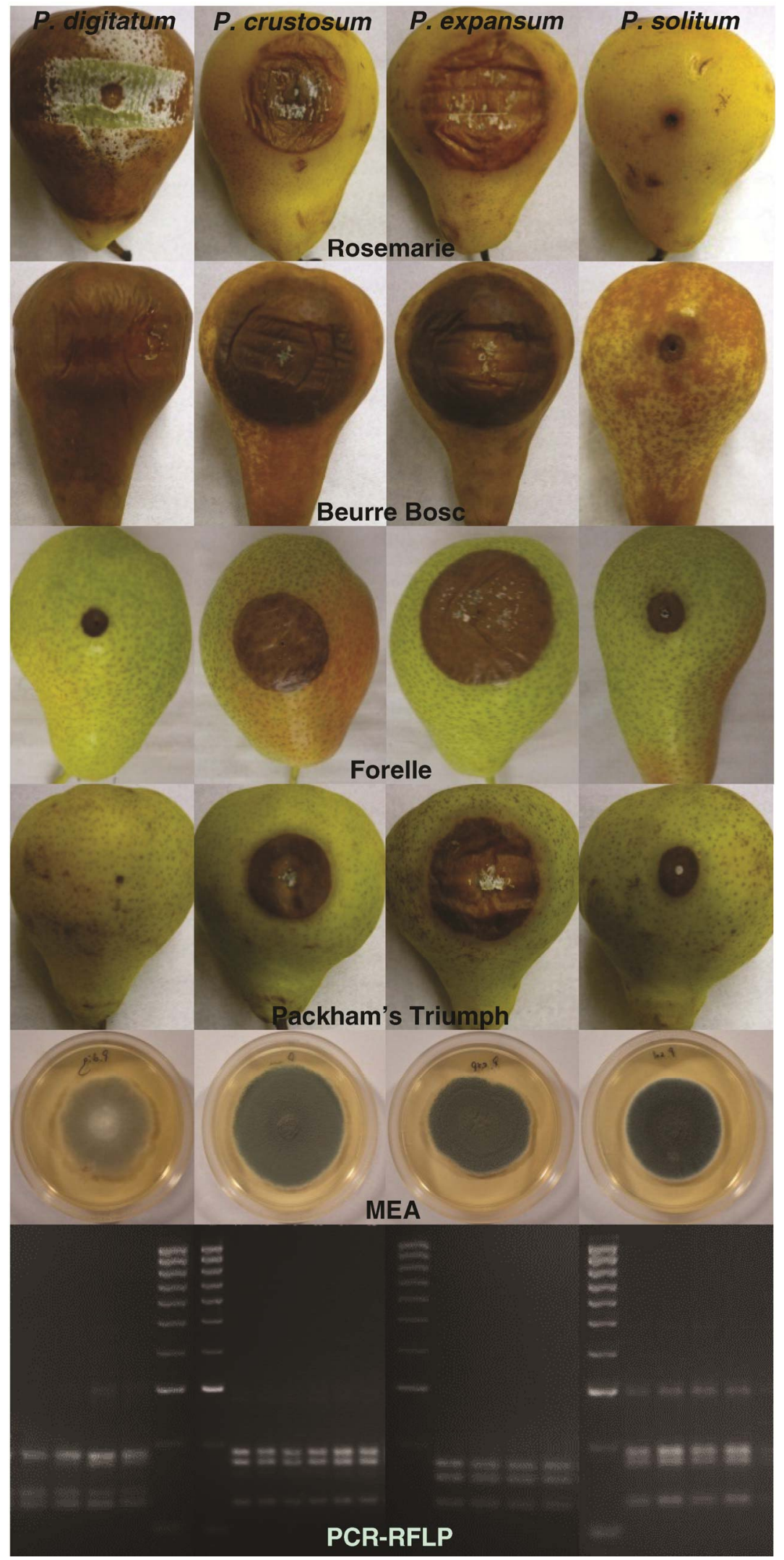

Fig. 5. Penicillium sp. (columns, left to right: Penicillium digitatum, $P$. crustosum, $P$. expansum, and $P$. solitum) symptom expression on pear cultivars (rows, top to bottom: 'Rosemarie', 'Beurre Bosc', 'Forelle', and 'Packham's Triumph'), cultures (malt extract agar [MEA]), and polymerase chain reaction restriction fragment length polymorphism (PCR-RFLP) of restriction-digested DNA (Bfal restriction enzyme) separated on $3 \%$ agarose gel. 
the isolated lesions from the market fruit. Vilanova et al. (35) described reactions of $P$. digitatum infections on Golden Smoothee apple but restricted the descriptions to "no decay development", with limited disease symptoms or hypersensitive reaction. The host resistance responses and infection reactions of $P$. digitatum described on Golden Smoothee were very similar to symptoms produced by $P$. digitatum on Golden Delicious apple in our study. $P$. digitatum was not isolated from the described infection sites on Golden Smoothee to confirm the identity of the organism causing the reaction. Books or publications with pome fruit Penicillium pathogen symptom descriptions are usually limited to descriptions or illustrations of one or two cultivars $(13,25,35)$. A compendium describing symptoms associated with different Penicillium sp. infections on various commercial cultivars is not readily available for industry and fruit inspectors. Similar to green and blue mold of citrus, there is a need to distinguish between decay caused by $P$. digitatum (distinct green mold) and the other blue-mold-causing Penicillium spp., as described in this study. This study further provides a more detailed description of blue mold symptoms over a range of apple and pear cultivars. $P$. expansum and $P$. crustosum symptoms were frequently related to bull's-eye rot symptoms which are commonly associated with Neofabraea (Jacks.) spp. (6,31). This may lead to the misidentification of the causal pathogen if no isolation and identification of the fungus is made. P. digitatum symptom expression on pear fruit and advanced symptom expression on apple fruit were reported for the first time in this article.

Pear, in general, was more susceptible and sensitive to Penicillium spp. decay than apple. Pear fruit are naturally more perishable (deteriorate faster) than apple fruit (13), adding to susceptibility and sensitivity. $P$. expansum and $P$. crustosum expressed pathogenicity over the cultivar ranges tested. $P$. expansum was considered the most aggressive, except on Beurre Bosc, Beurre Hardy, and Rosemarie. P. crustosum closely mimicked the pathogenic and aggression profile of $P$. expansum, generally expressing the second highest aggressiveness on the majority of cultivars tested (excluding Beurre Bosc, Beurre Hardy, and Rosemarie). P. solitum covered a broader cultivar range, had a higher disease incidence, and was more aggressive (larger lesions) on pear cultivars than on apple cultivars.

Penicillium spp. isolates from different environments (isolated from pear and citrus chains) did not produce significantly different lesion sizes on pear fruit. This finding confirms that environmental isolates from different origins represent a source of natural inoculum (30) for varying fruit types. The compilation of fruit from different origins, received in a central port or holding facility and sometimes even being repacked prior to further distribution in the

same supply chain, may increase the likelihood of cross-contamination. It also shows that $P$. digitatum and $P$. expansum originating from the citrus-chain environment produced lesion sizes and symptoms similar to the $P$. digitatum and $P$. expansum isolates from the pear environment.

The cold-storage test results showed that a change in environmental conditions can have a significant influence on pathogenicity, aggressiveness, and symptom expression. $P$. expansum was the only species that produced large lesions under cold-storage conditions that simulate commercial practices. The results correspond with findings from Vilanova et al. (35), indicating that $P$. expansum can infect, invade, and produce symptoms in the cold chain. $P$. crustosum was unable to produce large lesions at the cold-storage conditions tested compared with the big lesions under roomstorage conditions. Penicillium spores are able to tolerate extremely low temperature conditions and germinate when conditions become favorable for growth $(24,26)$. This can occur when the cold chain is broken during the extended supply chain. Thus, P. crustosum may be able to produce lesions on Golden Delicious apple once the fruit exit cold storage. $P$. digitatum is able to germinate at $4^{\circ} \mathrm{C}(20)$ and $P$. solitum is able to produce symptoms at $-1{ }^{\circ} \mathrm{C}(22)$ but the low sensitivity of Golden Delicious toward the two Penicillium spp. made it difficult to evaluate temperature-based disease sensitivity of the species on the apple cultivar. The growth patterns produced by $P$. expansum and $P$. digitatum in cold storage were similar to those described by Vilanova et al. (35). Thus, the results correspond, although the higher temperature in this study $(6.2 \pm$ 1.7 versus $0^{\circ} \mathrm{C}$ ) resulted in a shorter lag phase and faster growth rate for $P$. expansum. Future research should include cold-storage trials with a range of cultivars with varying susceptibility levels This will allow the identification of temperature-based disease sensitivity of specific Penicillium spp. depending on host susceptibility.

Table 5. Identified Penicillium $\beta$-tubulin gene sequences

\begin{tabular}{lcc}
\hline Isolate number & Sequence identification & $\begin{array}{c}\text { GenBank accession } \\
\text { number }\end{array}$ \\
\hline 8 & Penicillium solitum & KF303072 \\
28 & P. expansum & KF303073 \\
32 & P. expansum & KF303074 \\
54 & P. digitatum & KF303075 \\
58 & P. digitatum & KF303076 \\
78 & P. crustosum & KF303077 \\
109 & P. brevicompactum & KF303079 \\
110 & P. brevicompactum & KF303080 \\
111 & P. brevicompactum & KF303081 \\
\hline
\end{tabular}

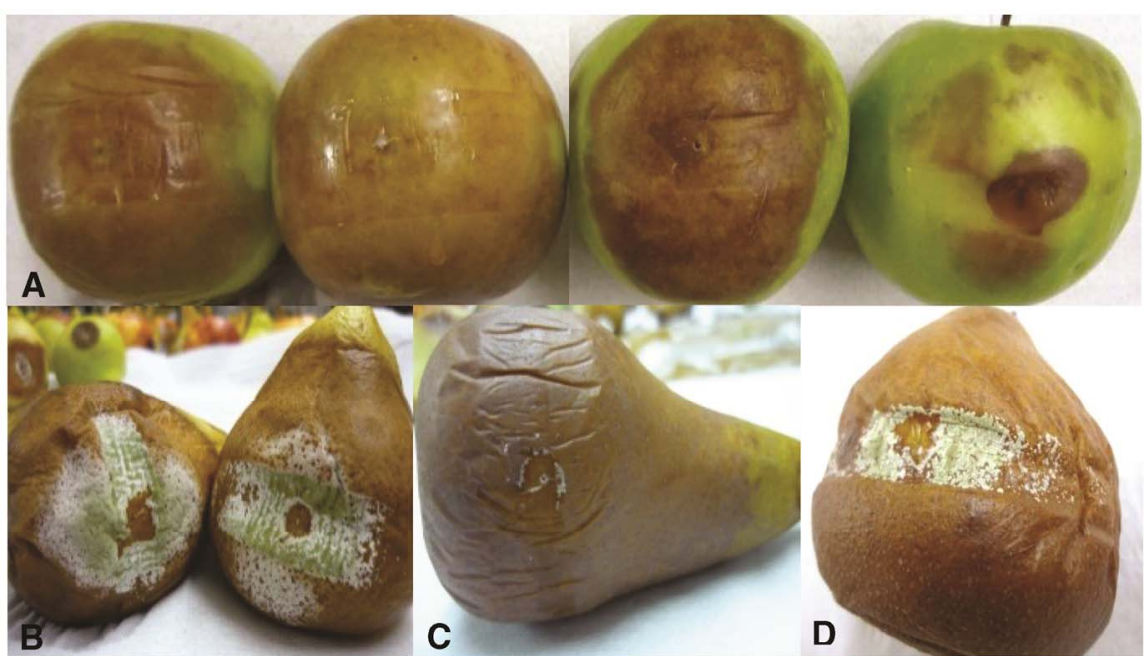

Fig. 6. Penicillium digitatum disease symptoms on pome fruit. A, 'Granny Smith'; B, 'Rosemarie'; C, 'Beurre Bosc'; and D, 'Beurre Hardy'; A = 11 and B-D = 7 days of incubation. 
Fruit designated for export remains in the supply chain for an extended period of time and often is repacked in facilities that do not necessarily comply with the same quality standards as is required in packinghouses at the beginning of the supply chain. Therefore it is hypothesized that losses at the consumer end of the chain can be partly due to improper handling, breaking of the cold chain, and sometimes repacking of fruit in facilities that do not have to comply with the same voluntary (but de facto compulsory) standards.

Conclusion. All tested species ( $P$. expansum, $P$. crustosum, $P$. digitatum, $P$. solitum, and $P$. brevicompactum) were pathogenic on pear but only the former four proved to be pathogenic on apple. $P$. digitatum, a known citrus pathogen, caused lesions on several pear and apple cultivars tested. This is the first report of $P$. digitatum obtained from a citrus-chain environment showing high aggressiveness (exceeding that of $P$. expansum) on pear (Rosemarie, Beurre Bosc, and Beurre Hardy) and causing rot on apple (Granny Smith and Cripps Pink). These pear cultivars have been described by the fruit industry as the most prone to decay at the retail end of the supply chain, resulting in significant financial losses. Differences in aggressiveness and host specificity were found among the isolates. $P$. expansum and $P$. crustosum were pathogenic on all cultivars tested whereas $P$. digitatum and $P$. solitum had narrower host cultivar ranges. $P$. expansum and, to a lesser extent, $P$. crustosum are known as the more typical postharvest pathogens on pome fruit. $P$. digitatum was identified as an opportunistic pathogen on pome fruit that can result in rapid pome fruit losses at the market end of the supply chain depending on sanitation in the storage, shipping, or marketing environments; temperature management during shipping and marketing; and host susceptibility as related to cultivar and fruit maturity.

\section{Acknowledgments}

Financial support was provided by the Department of Science and Technology, Fresh Produce Exporters Forum Postharvest Innovation Programme, the South African Apple and Pear Producers Association (administered by Fruitgro Science), and the Technology and Human Resources for Industry Programme (TP 2011071100006). Additionally, this work is based on the research supported, in part, by a number of grants from the National Research Foundation of South Africa (UID: 78566 [NRF RISP grant for the ABI3500] and student support). We thank R. Jacobs and I. Scholtz for providing the Penicillium isolates; T. T. Ghebremariam for statistical support; Z. Zulu for molecular support; L. Louw for trial assistance; and W. J. Janisiewicz (United States Department of Agriculture-Agricultural Research Service, Kearneysville, WV), M. Reinecke (Ceres Fruit Growers, Western Cape Province), and H. Griessel (Tru-Cape, Western Cape) for editorial input.

\section{Literature Cited}

1. Agrios, G. N. 2005. Plant Pathology, 5th ed. Elsevier Academic Press, San Diego, CA.

2. Amiri, A., and Bompeix, G. 2005. Diversity and population dynamics of Penicillium spp. on apples in pre- and postharvest environments: consequences for decay development. Plant Pathol. 54:74-81.

3. Bardas, G. A., Tzelepis, G. D., Lotos, L., and Karaoglanidis, G. S. 2009. First report of Penicillium glabrum causing fruit rot of pomegranate (Punica granatum) in Greece. Plant Dis. 93:1347.

4. Bower, J. H., Biasi, W. V., and Mitcham, E. J. 2003. Effect of ethylene in the storage environment on quality of 'Bartlett pears'. Postharvest Biol. Technol. 28:371-379.

5. Campbell, N. A., and Reece, J. B. 2002. Biology, 6th ed. Benjamin/ Cummings Publishing, San Francisco.

6. Gariepy, T. D., Rahe, J. E., Lévesque, C. A., Spotts, R. A., Sugar, D. L., and Henriquez, J. L. 2005. Neofabraea species associated with bull's-eye rot and cankers of apple and pear in the Pacific Northwest. Can. J. Plant Pathol. 27:118-124.

7. Glass, N. L., and Donaldson, G. C. 1995. Development of primer sets designed for use with the PCR to amplify conserved genes from filamentous Ascomycetes. Appl. Environ. Microbiol. 61:1323-1330.

8. Holmes, G. J., and Eckert, J. W. 1999. Sensitivity of Penicillium digitatum and $P$. italicum to postharvest citrus fungicides in California. Phytopathology 89:716-721.

9. Hortgro. 2012. Key deciduous fruit statistics 2012. Horticultural Group. Online publication. http://www.hortgro.co.za

10. Janisiewicz, W. J. Saftner, R. A, Conway, W. S., and Forsline, P. L. 2008.
Preliminary evaluation of apple germplasm from Kazakhstan for resistance to postharvest blue mold in fruit caused by Penicillium expansum. HortScience 43:420-426.

11. Johnston, C. L. 2008. Identification of Penicillium species in South African litchi export chain. M.Sc. dissertation, Department of Microbiology and Plant Pathology, University of Pretoria, Pretoria, Gauteng, South Africa.

12. Jones, A. L., and Aldwinckle, H. S., eds. 1990. Compendium of Apple and Pear Diseases. American Phytopathological Society, St. Paul, MN.

13. Kader, A. A. 2002. Postharvest Technology of Horticultural Crops. 3rd ed. University of California Agricultural and Nutritional Resources Publication 3311, Richmond, CA.

14. Kim, J.-H., Lee, W.-H., Cheong, S.-S., Choi, J.-S., Ryu, J., and Choi, Y.-G. 2005. Identification and characteristics of Penicillium spp. isolated from postharvest decay of pear. Res. Plant Dis. 8:107-112.

15. Lara, I., and Vendrell, M. 1998. Relationships between ethylene, abscisic acid and quality during postharvest storage of 'Granny Smith' apples. Postharvest Biol. Technol. 13:11-18.

16. Moslem, M., Abd-Elsalam, K., Yassin, M., and Bahkali, A. 2010. First morphomolecular identification of Penicillium griseofulvum and Penicillium aurantiogriseum toxicogenic isolates associated with blue mold on apple. Foodborne Pathog. Dis. 7:857-861.

17. Oliveri, C., Campisano, A., Catara, A., and Cirvilleri, G. 2007. Characterization and fAFLP genotyping of Penicillium strains from postharvest samples and packinghouse environment. J. Plant Pathol. 89:29-40.

18. Peter, K. A., Vico, I., Gaskins, V., Janisiewicz, W. J., Saftner, R. A., and Jurick, W. M., II. 2012. First report of Penicillium carneum causing blue mold on stored apples in Pennsylvania. Plant Dis. 96:1823.

19. Pianzzola, M. J., Moscatelli, M., and Vero, S. 2004. Characterization of Penicillium isolates associated with blue mold on apple in Uruguay. Plant Dis. 88:23-28.

20. Plaza, P., Usall, J., Teixidó, N., and Viñas, I. 2002. Effect of water activity and temperature on germination and growth of Penicillium digitatum, $P$ italicum and Geotrichum candidum. J. Appl. Microbiol. 94:549-554.

21. Roslan, H. A., Ngo, C. S., and Muid, S. 2010. Genetic diversity of Penicillium species isolated from various sources in Sarawak, Malaysia. J. Cell Mol. Biol. 7 and 8:13-23.

22. Sanderson, P. G., and Spotts, R. A. 1995. Postharvest decay of winter pear and apple fruit caused by species of Penicillium. Phytopathology 85:103110 .

23. Sholberg, P. L., and Haag, P. D. 1996. Incidence of postharvest pathogens of stored apples in British Columbia. Can. J. Plant Pathol. 18:81-85.

24. Smilanick, J. L., and Mansour, M. F. 2007. Influence of temperature and humidity on survival of Penicillium digitatum and Geotrichum citriaurantii. Plant Dis. 91:990-996.

25. Snowdon A. L. 1990. Postharvest Diseases and Disorders of Fruit and Vegetables, Volume 1: General Introduction and Fruit. Manson Publishing, London.

26. Sonjak, S., Frisvad, J. C., and Gunde-Cimerman, N. 2006. Penicillium mycobiota in arctic subglacial ice. Microb. Ecol. 52:207-216.

27. South African Department of Agriculture, Forestry and Fishery. 2009. Act No. 119 of 1990, regulations relating to the grading, packing and marking of apples intended for sale in the republic of South Africa. Gov. Gaz. No. 32254:3-21.

28. South African Department of Agriculture, Forestry and Fishery. 2009. Act No. 119 of 1990, regulations relating to the grading, packing and marking of pears destined for sale in the republic of South Africa. Gov. Gaz. No. 32254:23-38

29. Spadaro, D., and Gullino, M. L. 2004. State of the art and future prospects of the biological control of postharvest fruit diseases. Int. J. Food Microbiol. 91:185-194.

30. Spotts, R. A. 1986. Relationships between inoculum concentrations of three decay fungi and pear fruit decay. Plant Dis. 70:386-389.

31. Spotts, R. A., Cervantes, L. A., and Mielke, E. A. 1999. Variability in postharvest decay among apple cultivars. Plant Dis. 83:1051-1054.

32. Spotts, R. A., Sanderson, P. G., Lennox, C. L., Sugar, D., and Cervantes, L. A. 1998. Wounding, wound healing and staining of mature pear fruit. Postharvest Biol. Technol. 13:27-36.

33. Van Eeden, M., and Korsten, L. 2013. Alternative disease assessment method for Cercospora spot (Pseudocercospora purpurea (Cooke) Deighton) of avocado (Persea americana Mill.). Curr. Biotechnol. 2:106-113.

34. Vermeulen, H., Jordaan, D., Korsten, L., and Kirsten, J. 2006. Private standards, handling and hygiene in fruit export supply chain: a preliminary evaluation of the economic impact of parallel standards. Working Pap. No. 2, Department of Agricultural Economics, University of Pretoria, Pretoria, Gauteng, South Africa. Online publication. www.researchgate.net

35. Vilanova, L., Teixidó, N., Torres, R., Usall, J., and Viñas, I. 2012. The infection capacity of $P$. expansum and $P$. digitatum on apples and histochemical analysis of host response. Int. J. Food Microbiol. 157:360-367.

36. Villalobos-Acuña, M., and Mitcham, E. J. 2008. Ripening of European pears: The chilling dilemma. Postharvest Biol. Technol. 49:187-200. 